\title{
Ham Petrol İthalatı ve Büyüme
}

\author{
DOI: $10.26466 /$ opus.552784 \\ * \\ Zehra Doğan Çalıskan* - Mehmet Çakmak** \\ * * Dr. Öğr. Üyesi, Bolu Abant İzzet Baysal Üni., Gerede Uyg. Bilimler Y.O. Gerede/Bolu /Türkiye \\ E-Posta: zehradogan@ibu.edu.tr \\ ORCID: $\underline{0000-0002-7853-1966}$ \\ *Arş. Gör. Bolu Abant İzzet Baysal Üni., Gerede Uygulamalı Bilimler Y.O. Gerede / Bolu / Türkiye \\ E-Posta: mehmet.cakmak@ibu.edu.tr \\ ORCID: $\underline{0000-0002-6128-5607}$
}

Öz

Petrol bir enerji kaynağı olarak özellikle 20. yüzyıldan itibaren ülkeler arası büyüme farklılıklarının açıklanmasında önemli bir değişken olarak değerlendirilmektedir. Uluslararası iktisat literatüründe yer alan Faktör Donatımı (Heckscher-Ohlin) teorisine göre, bir ülke hangi üretim faktörüne zengin olarak sahipse, o faktörün yoğun biçimde kullanıldığı mallarda karşılaştırmalı üstünlük elde eder. Dolayısıyla uzmanlaştı̆̆ı bu malları ihraç ederken, kıt miktarda sahip olduğu mallart ithal eder. Bu teori temel anlamda bir ülkenin doğal kaynaklar bakımından üstün olduğu alanlarda üreterek uzmanlaştığı malları, bu kaynakların kıt olduğu ülkelere ihraç ederek büyümesini vurgulamaktadır. Günümüzde ham petrol bakımından bazı ülkeler ihracatçı konumdayken bazıları da ithalatçı konumdadır. Bu bağlamda petrol kaynă̆ı olmayan ülkeler üretimin devamlılı̆̆ı için petrol ithali yoluna gitmektedirler. Büyümenin devamlılı̆̆ını sağlayan petrol ithalatı ile büyüme oranları arasında sıkı bir ilişki bulunmaktadır. Bu bakımdan çalışmada Türkiye'de 1997-2017 dönemi için petrol ithal miktarı ile büyüme arasında nasıl bir ilişki olduğu VAR (Vektör Otoregresif Model) modeli kapsaminda incelenmiştir. Bu bağlamda Granger Nedensellik, Johansen Eşbütünleşme, Varyans Ayrıştırma ve Etki-Tepki Analizleri uygulanmıştır. Analiz sonucunda değişkenler arası uzun dönemli bir ilişki ile büyümeden petrol ithalatına doğru tek yönlü bir nedensellik ilişkisi bulgulanmıştır.

Anahtar Kelimeler: Petrol ithalatı, büyüme,VAR modeli 


\title{
Crude Oil Imports and Growth
}

\begin{abstract}
Petroleum is an energy source that has been considered as a crucial variable in defining the growth differences between countries, especially since the $20^{\text {th }}$ century. According to the Factor Endowment (Heckscher-Ohlin) Theory in the international economics literature, a country has a comparative advantage in the production of those goods in which its abundant production factor is extensively used. Thus, while exporting those goods on which the country specializes, it imports those goods that are scarce. This theory basically emphasizes the economic growth of a country maintained by exporting those goods, that are produced in the sectors at which the country specializes in utilizing its abundantly endowed natural resources, to the countries where such resources are scarce. Nowadays, some countries are crude petroleum exporters, whereas some others are importers. In this context, non-petroleum-exporting countries are importing petroleum for the continuity of their production process. There is an intense relationship between petroleum imports, which ensure the continuity of growth and growth rates. In this regard, the VAR (Vector Autoregression) model is utilized in the study over the period of 1997-2017 to analyze the extent of the relationship between the amount of imported petroleum and economic growth in Turkey. In this context; Granger Causality, Johansen Cointegration, Variance Decomposition, and Impulse-Response Analyses are performed. As a result of the conducted analyses, a long-term relationship between the variables is detected, and a unilateral causality running from economic growth towards petroleum imports relationship is found.
\end{abstract}

Keywords: Oil Import, Growth, VAR model 


\section{Giriş}

Uluslararası iktisat literatüründe yer alan Faktör Donatımı (HeckscherOhlin) teorisine göre, bir ülke hangi üretim faktörüne zengin olarak sahipse, o faktörün yoğun biçimde kullanıldığı mallarda karşılaştırmalı üstünlük elde eder. Dolayısıyla uzmanlaştı̆̆ bu malları ihraç ederken, kıt miktarda sahip olduğu malları ithal eder. Bu teori temel anlamda bir ülkenin doğal kaynaklar bakımından üstün olduğu alanlarda üreterek uzmanlaştığı malları, bu kaynakların kıt olduğu ülkelere ihraç ederek büyümesini vurgulamaktadır. Bu açıdan bakıldığında doğal kaynaklara her geçen gün talep artmaktadır. Bu kaynaklardan olan ham petrol, hem enerji kaynağ rinden olan benzin, motorin ve sıvı gaz kamu sektörünün ve özel sektörün enerji ihtiyacını karşıladığı gibi bireylerin de ihtiyacını karşılamaktadır. Ayrıca petrolün ilaç, solvent, gübre, pestisit ve plastik gibi birçok kimyasal ürünün de ham maddesi olabilme yönü de vardır. Bu bakımdan hem enerji talebini hem de kimyasal ürünlere ilişkin sektörlerin talebini karşılayıcı özelliğe sahiptir.

Günümüzde ham petrol bakımından bazı ülkeler ihracatçı konumdayken bazıları da ithalatçı konumdadır. Türkiye'de de ham petrol talebinin bir kısmı kendi yer altı kaynaklarından elde edilirken büyük bir kısmı da ithal edilmektedir. Ham petrol ithalatı bir ülkede enerji talebini karşılarken aynı zamanda ham petrolün bileşenlerinin kullanımıyla sağlanan çıtının bir kısmı ihraç ediliyorsa ekonomik anlamda büyümeye katkısı olabileceği söylenebilir. Bu bağlamda petrol miktarı ile büyüme arasında bir ilişkiden söz edilebilir. Bu çalışma ekonomik büyümeye ham petrol ithalatının etkisini içeren bir analiz sunmaktadır. Bu amaçla, çalışmada Türkiye'de 1997-2017 dönemi için büyüme ve ham petrol ithalatı ilişkisi incelenmiştir.

\section{Literatür}

Ham petrol ithalatı ve ekonomik büyüme arası ilişkiyi inceleyen önceki çalışmalara dair bir araştırma yapıldığında genel anlamda ham petrol ithalatının doğrudan ya da dolaylı olarak ekonomik göstergelerde yarattığı etkilerinin incelendiği gözlenmiştir. Şöyle ki bazı çalışmalarda ithal ham 
petrol talebinin elastikiyetine bak1lırken analize ham petrol ithalat verileri ve ekonomik büyüme de katılmıştır. Bazılarında ise enerji tüketimi ile kalkınma analizi yapılırken ham petrol ithalatı ile ekonomik büyüme de ilişkilendirilmiştir. Bazı çalışmalarda ise bu ilişki doğrudan ele alınmıştır. Çalışmamızın temel konusu ham petrol ithalatının ülkenin ekonomik büyümesine olan etkisini incelemek olduğundan, bu ilişkiyi doğrudan ya da dolaylı olarak analiz eden makalelere ilişkin literatür taraması şöyle ifade edilebilir:

Chien-Chiang ve Chun-Ping (2007) çalışmasında Tayvan'da enerji tüketiminin (ithalat dâhil edilerek) ekonomik büyümeye etkisini doğrusal ve doğrusal olmayan modelleme ile incelenmiştir. Yazarlar bu çalışma kapsamında 1955-2003 yılları arasındaki verileri ele alırken GSYİH deflatörünü de analize katmışlardır. Eşik Değerli Otoregresif Model (Threshold Outoregressive Model-TAR) kullanılarak yapılan analiz sonucu enerji tüketimi ile reel GSYİH büyümesi arasındaki ilişkinin Tayvan'da ters bir U şekli şeklini aldığına dair kanıtlar ortaya konulmuştur.

Altınay (2007) çalışmasında, 1980-2005 yılları arası yıllık zaman serilerini kullanarak Türkiye'de ham petrol talebinin kısa ve uzun vadeli esnekliklerini tahmin edilmiştir. Bu kapsamda söz konusu analize GSYİH deflatörü de katılarak analiz gerçekleştirilmiştir. Analiz kapsamında ARDL (Autoregressive Distributed Lag Bound Test- Otoregressif Dağıtılmış Gecikmeli Sınır Testi) testini kullanarak tahmini uzun dönem gelir esnekliğinin ve petrol talebinin fiyat esnekliği (sırasıyla, 0.61 ve 0.18 ) istatistiksel olarak önemli olduğu belirtilmiştir. Türkiye için kısa vadeli gelir esnekliği ve petrol talebinin fiyat esnekliği sirasıyla 0,64 (önemli) ve 0,10 (önemli) olarak tahmin edilmektedir. Petrol fiyatındaki \%1'lik bir artışın, kısa vadede petrol talebindeki \% 0.10 'luk bir düşüş ya da tam tersi bir etkisi vardır. Elde edilen tek farklı sonuç, uzun vadeli değerle neredeyse aynı olduğu bulunan kısa dönem gelir esnekliğidir.

Jabir (2009) çalışmasında, hem ham petrol ithalatı hem de yerli anlamda ham petrol üretimi ile GSYİH arasındaki ilişki analiz edilmiştir. Çalışma kapsamında yazar, ABD'nin 1973-2005 yılları arasındaki verilerini Vektör Hata Düzeltme modeli çerçevesinde analiz etmiştir. Yazara göre yapılan analizde GSYİH'deki artış ham petrol ithalatının tetikleyicilerindendir ve Eşbütünleşme ile şoklar da analize dâhil edilmiş, buna göre ilişkiye etkisinin yakınsama hızının 12 olduğunu tespit edilmiştir. 
Ghosh (2009) çalışmasında, Hindistan'da 1970-1971 ile 2005-2006 yılları arasındaki ham petrol ithalatı verilerini alarak Reel GSYİH ile arasındaki ilişkiyi analiz edilmiştir. ARDL (Autoregressive Distributed Lag Bound Test- Otoregressif Dağıtılmış Gecikmeli Sınır Testi) testi ile yapılan analiz sonucunda Hindistan'da ithal edilen ham petrolün uzun vadeli gelir esnekliğinin 1,97 olduğunu ve ekonomik büyümeden ham petrol ithalatına kadar tek yönlü ve uzun vadeli bir nedensellik olduğunu tespit edilmiştir.

Ziramba (2010) çalışmasında, Güney Afrika'da ithal ham petrole olan talebi gelir ve fiyat esnekliği bağlamında analiz edilmektedir. Bunun 19802006 yılları arası veriler zaman serisi analizi kapsamında eşbütünleşme analizi yapılmıştır. Söz konusu çalışmada yazar, esnekliğe dair analizine GSYİH'yi de katarak Birim KÖK testi de uygulamıştır. Buna göre ham petrol ithalat talebi ile gelir ve fiyat arasında uzun vadeli bir ilişki olduğu tespit edilmiştir. Kısa vadede bunu açıklamanın istatistiki olarak anlamsız olabileceği vurgulanmıştır. Sonuç olarak $-0,147$ ve 0,429 'luk tahmini uzun vadeli gelir ve fiyat elastikiyeti değeri ithal ham petrole dair talebin gelir ve fiyat açısından elastik olmadığını göstermekte olduğunu ve bunu da ham petrol ithalatından reel GSYİH'ye doğru uzun vadede tek yönlü bir nedensellik çıkarımı ile desteklenmiştir.

Ediger ve Berk (2011) çalışmasında, 4 faktör temelinde (Birincil Enerji Tüketimi, Kişi Başına Elektrik Tüketimi, GSYİH Enerji Yoğunluğu ve Kişi Başına Karbondioksit Emisyonu) Ham Petrol İthalatı Hassasiyet Endeksi oluşturarak ithalatın etkisini içeren bir analiz yapılmıştır. Yazarlar bu çalışmada, söz konusu 4 faktöre dair 1968-2008 yılları arası veriler ışığında PCA (Principle Component Analysis-Temel Bileşen Analizi) metodu ile analiz yapmışlardır. Buna göre elde edilen denklem çerçevesinde 4 faktörün çok benzer ağırlıklara sahip olduğunu (sırasıyla \% 28,4, \% 26,9; \% 22,7 ve \% 21,9) ve Türkiye'nin Ham Petrol İthalatı Hassasiyet Endeksi'ne neredeyse eşit katkıda olduğunu tespit edilmiştir.

Hyun ve Jungho (2013) çalışmasında, 1986-2010 yılları arasında Güney Kore'nin ham petrol ithalatı hacmi, ekonomik büyüme ve ithal ham petrolün fiyatı arasındaki kısa ve uzun vadeli ilişkileri değerlendirilmiştir. Söz konusu çalışmada veriler ARDL (Autoregressive Distributed Lag Bound Test- Otoregressif Dağıtılmış Gecikmeli Sınır Testi) testi ile analiz edilmiştir. Buna göre Güney Kore'nin ham petrole olan ithalat talebi ile 
seçilen değişkenler arasında uzun vadeli bir ilişki olduğu sonucuna varılmıştır. Gelir seviyesinin, Kore'nin ham petrol ithalatının uzun vadeli davranışının ham petrol fiyatından daha güçlü bir belirleyici olduğu da tespit edilmiştir.

Zhang ve Diğ.(2013) çalışmasında, Çin'in ham petrol ithalatı bağlamında fiyat değişiminin ülkenin GSYİH'sine etkisi araştırılmıştır. Bu amaçla 2000-2011 arasında söz konusu ilişki analizi için veriler esas alınmıştır. Yazarlar çalışmada, Doğrusal Programlama ile veri analizi yapmışlardır. Bu analize göre Çin, uluslararası ham petrol fiyatlarındaki dalgalanma nedeniyle aylık 47.078 milyar Yuan kadar GSYİH kaybına maruz kalacağı sonucuna ulaşılmıştır.

Tiwari (2015) çalışmasında, Hindistan ekonomisine dair GSYİH, ham petrol üretimi ve ithalatı arasındaki statik ve dinamik nedensellik ilişkisini analiz edilmiştir. Yazar zaman serisi analizi bağlamında Birim KÖK testi ve eşbütünleşme analizi yaparak kısa vadeye nazaran uzun vadede bu ilişkinin GSYİH'de yarattığı dengesizliğin uzun vadede yılda yüzde 41,5'lik ayarlama hızı ile düzeltileceğini tespit etmiştir.

Yapraklı ve Kaplan (2015) çalışmasında, Türkiye'nin 1970-2013 yılları arasındaki ham petrol ithalatına dair talebin gelir ve fiyat esnekliği üzerinde bir analiz yapılmıştır. Bu analiz yapılırken veri setine Türkiye'nin GSYİH'si de eklenmiştir. Yazarlar söz konusu çalışmalarında birim kök testi ve eşbütünleşme analizi ile yaptıkları analiz sonucunda ham petrol ithalatına dair uzun vadede talebin gelir ve fiyat esnekliğinin elastik olmadığı sonucuna varmışlardır. Ham petrol ithalat talebinin gelir ve fiyat bakımından kısmi esneklikleri sırasıyla 0.18 ve -0.25 tir ve $\% 1$ düzeyinde istatistiksel olarak anlamlı olduğu belirtilmiştir. Yine yazarlar, GSYİH ya da ham petrol fiyatlarındaki\% 1'lik artış, uzun vadede, sırasıyla, \% 0.18'lik bir artış veya ham petrol ithalat talebinde\% 0.25 'lik bir düşüşe neden olduğunu belirtmişlerdir.

Öztürk ve Arısoy (2016) çalışmasında, ham petrol ithalatına dönük talebi modellemek için fiyat ve gelir tahminlemesi yapılmıştır. Bu kapsamda Türkiye'nin 1966-2012 yılları arasındaki ham petrol tüketimi, ham petrol fiyatları ve reel GSYİH verileri ele alınmıştır. Söz konusu çalışmada yazarlar, TVP (Time-Varying Parameters- Zamanla Değişen Parametreler) yaklaşımı çerçevesinde verileri analiz etmişler; gelir ve fiyat esnekliğinin istatistiksel olarak anlamlı olduğunu saptamışlardır. Gelir esnekliğinin 
değerini 1.182 bularak Türkiye'de ham petrol ithalatının gelir seviyesindeki değişikliklere daha duyarlı olduğunu ifade etmişlerdir.

Marbuah (2017) çalışmasında, Gana'nın 1980-2012 yılları arası ham petrol ithalatı verilerinden yola çıkarak bir talep modellemesi çıkarılmaktadır. Söz konusu talebin dinamiklerinden olan Reel GSYİH'yi de analizine katılmıştır. Söz konusu çalışmada ARDL (Autoregressive Distributed Lag Bound Test- Otoregressif Dağıtılmış Gecikmeli Sınır Testi) testini kullanırken aynı zamanda eşbütünleşmeye de bakılmıştır. İthal ham petrol talebinde kısa vadede fiyat esnek değilken uzun vadede esnek olduğu tespit edilmiştir.

Özaytürk ve Alper (2017) çalışmasında, 2000-2013 yılları arasında ham petrol ithalatının Türkiye'nin de dâhil olduğu 11 OECD ülkesi açısından cari işlemler açığına etkisini analiz edilmektedir. En Uygun Genelleştirilmiş En Küçük Kareler Yöntemi (FGLS; Feasible Generalized Least Square) ile analiz yapılmıştır. Yazarlara göre, Gayrisafi Yurtiçi Hasıla (GSYİH), ithal petrol miktarı ve finansal gelişmişlik düzeyi ile cari açık arasında pozitif yönlü bir ilişki mevcut olup cari açı̆̆a en yüksek etkiyi ithal petrol miktarı yapmaktadır.

Sun vd. (2017) çalışmasında, ham petrol ithalatının Çin ekonomisi aç1sından sistematik riskini analiz edilmiştir. Bunun için 2003-2013 yılları arasındaki 24 ana petrol üreticisinin ham petrol talebi göz önüne alınmıştır. Bu analize GSYİH de katılmıştır. Söz konusu çalışmada, 4'lü faktör analizi yapılmış ve özellikle 2008-2009 yıllarındaki küresel krizinde etkisi ile risk doğurabildiği vurgulanmıştır. Bozulma riskinin de 0,6 ile 1,4 arasında değiştiğini tespit edilmiştir.

Bostan ve Ravanoğlu (2018) çalışmasında, Kırgızistan'da enerji tüketimi ile ekonomik büyüme arası ilişkiyi incelenmiş olup enerji tüketiminin içerisine ham petrol ithalatı da katılmıştır. Bu amaçla 1995-2012 yılları arası veriler analize katılmıştır. Vektör Hata Düzeltme (VEC) modeline göre hata düzeltme katsayısı -0.4876 ve p-değeri 0.0233 bulunmuştur; bunun anlamı (i) kömür tüketimi, elektrik tüketimi ve petrol tüketiminden kişi başına Reel GSYİH'ye doğru uzun dönemli eşbütünleşme ilişki vardır, (ii) hata düzeltme mekanizması çalışmakta ve dengeden sapmaların \% 48.76'ı bir yıl içinde giderilmektedir. Son olarak eşbütünleşme katsay1ları Stock - Watson Dinamik EKK (DOLS) modeli ile tahmin edilmiş ve 
DOLS modeli ile enerji tüketiminden büyümeye doğru uzun dönemli ilişki tespit edilmiştir.

Cheng-Yih ve Chen-Jung (2018) çalışmasında, Tayvan'ın 1981-2016 yılları arasındaki ham petrol ithalatı miktarındaki değişimi ile ekonomik büyüme arasındaki ilişki analiz edilmektedir. Yazarlar çalışma sonucunda Tayvan'ın enerji ihtiyacının \% 98'i ithalat yoluyla karşılanmakta olduğunu ve bunun da GSYİH'nin yaklaşık \%15'ine eşit geldiğini ifade etmektedirler. Bu durumda artan ham petrol talebi nedeniyle oluşan ithalat artışı aynı zamanda petrol bağımlısı sektörlerin ihracatını da artırdığı için ülkenin ekonomik büyümesi ile yakından ilişkili olduğunu belirtmişlerdir.

\section{Veri Seti ve Yöntem}

Teorik ve ampirik literatür petrol ithalatı ile büyüme arasındaki yakın ilişkiyi açığa çıkarmıştır. Buna göre ham petrol ithalatı arttıkça büyümenin artması beklenmektedir. Öte yandan petrol ithalatı öncelikle büyümeyi artırırken enerji ödemeleri nedeniyle cari açı̆̆ 1 da artırabilir. Bu çalışmanın literatüre katkısı Türkiye için ilgili dönemde petrol ithalat miktarı ile büyüme miktarı arasında uzun dönemli ilişkiyi test etmesidir. Bu amaçla çalışmada Türkiye için Dünya Bankası veri setinden elde edilen 1997-2017 yılları arasındaki ham petrol ithalat miktarı ve büyüme oranı analize tabi tutulmuştur. Bu iki değişken arasındaki ilişkiyi test etmek amacıyla Vektör Otoregresif Model (VAR), Granger Nedensellik, Johansen Eşbütünleşme, Varyans Ayrıştırma ve Etki-Tepki Analizleri kullanılmıştır.

\section{Analiz Sonuçları}

Modelin ilk aşaması serilere durağanlık analizlerinin uygulanmasıdır. Analizde kullanılan değişkenler ve kurulan modeller zaman serisi özelliklerine sahip olduğundan başlangıçta serilere durağanlık analizleri uygulanması gerekmektedir. Bu bağlamda çalışmada serilere, literatürde yaygin biçimde kullanılan Genişletilmiş Dickey Fuller (ADF) birim kök testi uygulanmıştır. Çalışmada Türkiye'nin 1997-2017 döneminde gerçekleştirdiği petrol ithalatı ve büyüme değişkenleri değerlerinin durağan olup ol- 
madıkları araştırılmış iki değişkeninde düzey değerlerinde durağan olmadıkları ancak ilk farkları alındığında durağan hale geldikleri tespit edilmiştir. Tablo 1'de ADF birim kök testi sonuçları görülmektedir.

Tablo 1. Durağanlık Testi ADF İstatistiği Değerleri

\begin{tabular}{lcc}
\hline Değişken & Düzey değerleri için & Birinci fark değerleri için \\
\hline LNGSMH & 0.4759 & 0.0028 \\
LNPETROLITHALATI & 0.5738 & 0.0096 \\
\hline
\end{tabular}

Eşbütünleşme, düzeyde durağan olmayan serilerin aynı fark düzeylerinde durağan olmaları durumunda uzun dönemde birlikte hareket edip etmediklerini araştırmak üzere geliştirilmiştir. Granger nedensellik modeli seriler arasında ilişkinin varlığını sorgulamakta ve söz konusu ilişkinin yönünü belirlemek için kullanılmaktadır. Bu bağlamda seriler arası Garanger Nedensellik İlişkisi aşağıdaki denklemler ile ifade edilmektedir (Uzunöz ve Akçay, 2012, s.8).

Değişkenlerin benzer şoklardan etkilenip etkilenmedikleri hususu Johansen eş bütünleşme testi yardımıyla araştırılmıştır. Elde edilen bulgular 0,05 önem seviyesinde iki adet eş bütünleşik eşitlik bulunduğu göstermektedir. Tablo 2'de eşbütünleşme testi sonuçları görülmektedir.

Tablo 2. Johansen Eşbütünleşme Testi Sonuçlarn

\begin{tabular}{ccccccccccc}
\hline \multicolumn{3}{c}{ Hipotezler } & \multicolumn{3}{c}{ İz İstatistiği Değerleri } & \multicolumn{3}{c}{ Maksimum Öz Değer İstatistikleri } \\
Ho & $\mathbf{H} 1$ & $\begin{array}{c}\text { Öz } \\
\text { değer }\end{array}$ & $\begin{array}{c}\text { Test } \\
\text { istatis- } \\
\text { tiği }\end{array}$ & $\begin{array}{c}\mathbf{0 , 0 5} \\
\text { Kritik } \\
\text { değer }\end{array}$ & $\begin{array}{c}\text { Olasılı } \\
\mathbf{k}(\mathbf{p})\end{array}$ & $\begin{array}{c}\text { Öz } \\
\text { değer }\end{array}$ & $\begin{array}{c}\text { Test } \\
\text { istatis- } \\
\text { tiği }\end{array}$ & $\begin{array}{c}\mathbf{0 , 0 5} \\
\text { Kritik } \\
\text { değer }\end{array}$ & $\begin{array}{c}\text { Olasılı } \\
\mathbf{k}(\mathbf{p})\end{array}$ \\
\hline $\mathrm{r}=0$ & $\mathrm{r} \geq 1$ & 0.61267 & 22.1039 & 15.4947 & 0.0044 & 0.61267 & 17.0727 & 14.2646 & 0.0175 \\
$\mathrm{r} \leq 1$ & $\mathrm{r} \geq 2$ & 0.24384 & 5.03113 & 3.84146 & 0.0249 & 0.24384 & 5.03113 & 3.84146 & 0.0249 \\
\hline
\end{tabular}

Analizde kullanılan bir diğer test Granger Nedensellik testidir. Seriler arasında nedensellik olup olmaması durumu söz konusu serilerin eşbütünleşme durumları ile ilişkilendirilmektedir. Modelde kullanılan seriler uzun dönemde birlikte hareket ediyorlarsa eşbütünleşik seriler olarak adlandırılmaktadır. Bu durumda seriler düzey değerlerinde durağan ve eşbütünleşik değillerse VAR (Vektör Otoregresif Model) modeli kullanılarak nedensellikleri araştırılırken, seriler durağan değil ancak eşbütünle- 
şiklerse VECM (Vektör Hata Düzeltme Modeli) modeli kullanılarak nedensellikleri araştırılmaktadır (Çil-Yavuz, 2005, s.964). Değişkenler arasındaki ilişkinin yönünü belirlemek için yapılan Granger Nedensellik Testi sonuçları, büyümeden petrol ithalatına doğru tek yönlü bir nedensellik olduğunu ortaya koymaktadır. Tablo 3'de Granger Nedensellik Testi sonuçları görülebilir.

Tablo 3. Granger Nedensellik Sonuçları (2 Gecikmeli Model)

\begin{tabular}{|c|c|c|c|}
\hline Ho Hipotezi & & $\begin{array}{c}\text { F-İstatis- } \\
\text { tiği }\end{array}$ & Olasılık \\
\hline LNGSMH, LNPETROLITHALATI'nIn & & & \\
\hline $\begin{array}{l}\text { Granger nedeni değildir. } \\
\text { LNPETROLITHALATI, LNGSMH'nın }\end{array}$ & 19 & 5.14284 & 0.0212 \\
\hline Granger Nedeni değildir. & & 1.78179 & 0.2045 \\
\hline
\end{tabular}

VAR Modeli kurulmadan önce uygun gecikme uzunluğunun belirlenmesi gerekmektedir. Bu amaçla yapılan gecikme kriterlerini belirleme testi sonuçları Tablo 4 ' te yer almaktadır. Tabloya göre en fazla yıldız alan uygun gecikme 2 olarak görülmektedir.

Tablo 4. VAR Gecikme Kriterleri

\begin{tabular}{ccccccc}
\hline Gecikme & LogL & LR & FPE & AIC & SC & HQ \\
\hline 0 & -6.066119 & NA & 0.009399 & 1.008265 & 1.104838 & 1.013210 \\
1 & 20.83729 & $43.71803^{*}$ & 0.000541 & -1.854661 & $-1.56494^{*}$ & -1.839825 \\
2 & 26.08907 & 7.221207 & $0.000479^{*}$ & $-2.01113^{*}$ & -1.528266 & $-1.98640^{*}$ \\
3 & 27.06780 & 1.101073 & 0.000760 & -1.633476 & -0.957460 & -1.598858 \\
4 & 33.24860 & 5.408194 & 0.000685 & -1.906075 & -1.036912 & -1.861566 \\
\hline
\end{tabular}

VAR modelinin İstikrarlı olup olmadığı AR karakteristik köklerinin hesaplanan tablo değerlerinin 1'den küçük olması, dolayısı ile bu amaçla çizilen çemberin içinde değerler almasına bağlıdır. Tahmin sonuçlarına göre model istikrarlı görünmektedir. 


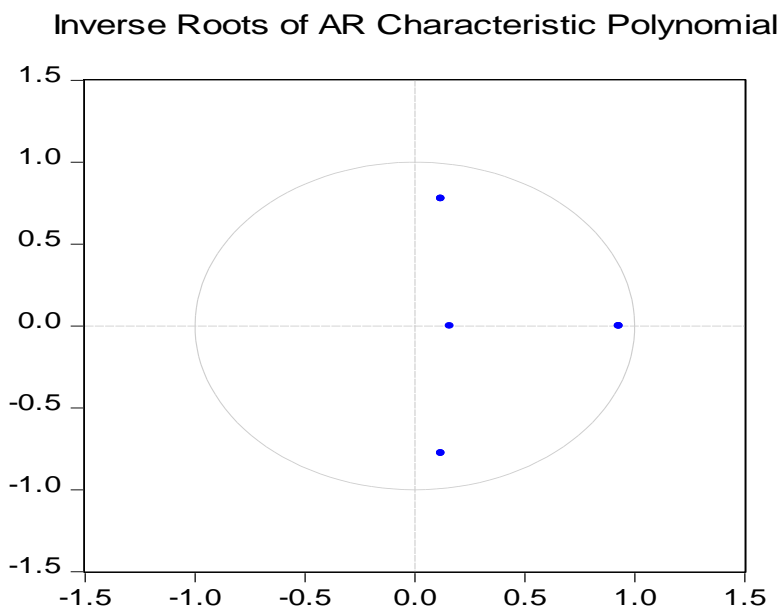

Şekil 1. AR Karakteristik Polinomu Ters Kökleri

Kurulan modelde otokorelasyon olup olmadığı LM testi yapılarak analiz edilmiş, söz konusu modelde ardışık bağımlılık sorununun olmadığ tespit edilmiştir. LM Otokorelasyon testi sonuçları Tablo 5 'te görülmektedir.

Tablo 5. LM Otokorelasyon Testi Sonuçları

\begin{tabular}{ccc}
\hline Gecikmeler & LM-istatistiği & Olasılik \\
\hline 1 & 8.009145 & 0.0912 \\
2 & 5.532763 & 0.2369 \\
3 & 0.815252 & 0.9364 \\
4 & 4.965976 & 0.2908 \\
5 & 0.766068 & 0.9429 \\
6 & 3.865520 & 0.4245 \\
7 & 0.800736 & 0.9383 \\
8 & 1.951302 & 0.7447 \\
9 & 3.190420 & 0.5265 \\
10 & 2.217934 & 0.6957 \\
11 & 3.288717 & 0.5107 \\
12 & 1.900127 & 0.7541 \\
\hline
\end{tabular}


Modelde değişen varyans sorunu olup olmadığı konusunda da değerlendirilmiş, incelenen test sonuçlarına göre değişen varyans olmadığ 1 kanaatine varılmıştır. Değişen varyans testi sonuçları Tablo 6'da görülmektedir.

Tablo 6. Değişen Varyans Testi Sonuçları

\begin{tabular}{ccc}
\hline Ki kare & Serbestlik Derecesi & Olasilık \\
\hline 29.67641 & 24 & 0.1957 \\
\hline
\end{tabular}

Hata terimlerinin normal dağılıp dağılmadığı hususunda yapılan Jarque-Bera Testi sonuçları, Normal dağılımın da mevcut olduğunu göstermiştir. Jarque-Bera Normallik Testi sonuçları Tablo 7' de görülmektedir.

Tablo 7. Jarque-Bera Normallik Testi

\begin{tabular}{cccc}
\hline Öğeler & Jarque-Bera Testi & Serbestlik derecesi & Olasılik \\
\hline 1 & 4.999095 & 2 & 0.0821 \\
2 & 2.162300 & 2 & 0.3392 \\
Ortak & 7.161396 & 4 & 0.1276 \\
\hline
\end{tabular}

Modelin uygunluk testlerini geçmesinin ardından LNBÜYÜME değişkeninin LNPETROLİTHALATI değişkeni üzerinde etkili olup olmadığ Varyans ayrıştırma tablosundan incelenebilir. Hesaplanan değerlere göre LNBÜYÜME'nin 10 dönem boyunca varyans içindeki payını arttırdığı dolayısı ile petrol ithalatı üzerinde etkili bir değişken olduğu anlaşılmaktadır. Varyans ayrıştırma değerleri Tablo 8'de görülmektedir.

Tablo 8. Varyans Ayrıştırma Tablosu

\begin{tabular}{|c|c|c|c|}
\hline Dönem & S.E & LNPETROLITHALATI & LNGSMH \\
\hline 1 & 0.245667 & 100.0000 & 0.000000 \\
\hline 2 & 0.336110 & 84.89902 & 15.10098 \\
\hline 3 & 0.387351 & 65.30074 & 34.69926 \\
\hline 4 & 0.405896 & 60.47205 & 39.52795 \\
\hline 5 & 0.426024 & 62.63085 & 37.36915 \\
\hline 6 & 0.451436 & 64.16101 & 35.83899 \\
\hline 7 & 0.470067 & 61.81806 & 38.18194 \\
\hline 8 & 0.481624 & 59.85421 & 40.14579 \\
\hline 9 & 0.489995 & 59.65080 & 40.34920 \\
\hline 10 & 0.499650 & 60.02597 & 39.97403 \\
\hline
\end{tabular}


Etki tepki analizine bakılarak GSMH'de meydana gelen bir birimlik standart şokun Petrol İthalatında ne kadarlık bir değişim yarattığı gözlenebilir. Değişim sürekli bir artış ifade ederse ele alınan değişkenin politika belirlemede etkin olduğu söylenebilecektir. Etki tepki analizi Tablo 9'da görülmektedir.

Tablo 9. Etki Tepki Analizi Tablosu

\begin{tabular}{ccc}
\hline DÖNEM & LNPETROLITHALATI & LNGSMH \\
\hline 1 & 0.245667 & 0.000000 \\
2 & 0.188569 & 0.130612 \\
3 & 0.045467 & 0.187092 \\
4 & 0.040631 & 0.114280 \\
5 & 0.118508 & 0.051969 \\
6 & 0.130706 & 0.072210 \\
7 & 0.076410 & 0.106443 \\
8 & 0.047366 & 0.093567 \\
9 & 0.066183 & 0.061269 \\
10 & 0.081463 & 0.054025 \\
\hline
\end{tabular}

Elde edilen sonuçlara göre büyümede meydana gelen 1 birimlik standart şok petrol ithalatında 3ncü dönemde 0,18 birimlik şoka sebep olmaktadır. Büyüme, petrol ithalatı üzerinde etkin bir değişkendir.

Tablo 10. VAR Granger Nedensellik Modeli

\section{Bağımlı Değişken: LNPETROLITHHALATI}

\begin{tabular}{llcc} 
Dişsal değişken & Ki kare & Serbestlik & Olasıllk \\
\hline LNGSMH & 10.28568 & 2 & 0.0058 \\
\hline
\end{tabular}

Bağımlı Değişken: LNBÜYÜME

\begin{tabular}{lccc} 
Dişsal değişken & Ki kare & Serbestlik & Olasılık \\
\hline LNPETROLİTHALATI & 3.563583 & 2 & 0.1683 \\
\hline
\end{tabular}

VAR Modeli Granger Nedensellik Testine göre de büyümeden petrol ithalatına doğru tek yönlü nedensellik ilişkisi olduğu tespit edilmiştir. Sonuçlar beklentiye uygun olarak büyümenin petrol ithalatı üzerinde etkili bir değişken olduğunu göstermektedir. 
Ham Petrol İthalatı ve Büyüme

Response to Cholesky One S.D. Innovations \pm 2 S.E.

Response of LNPETROLITHALATI to LNPETROLITHALATI

Response of LNPETROLITHALATI to LNGSMH
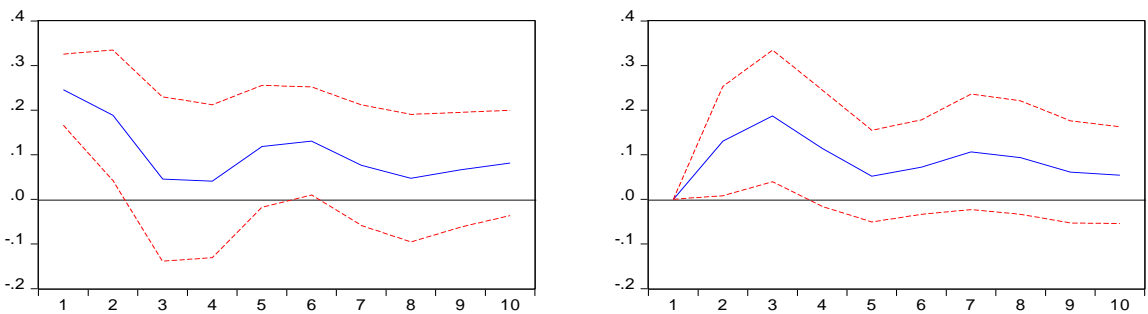

Response of LNGSMH to LNPETROLITHALATI

Response of LNGSMH to LNGSMH
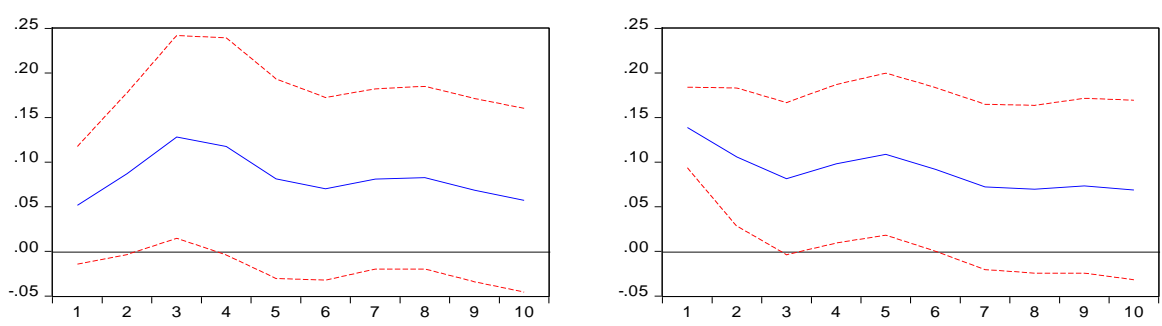

Şekil 2. Etki Tepki Grafikleri

Variance Decomposition

Percent LNPETROLITHALATI variance due to LNPETROLITHALATI

Percent LNPETROLITHALATI variance due to LNGSMH
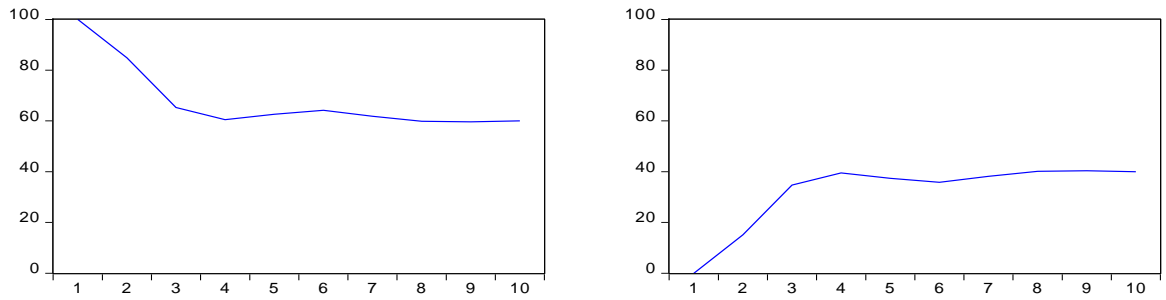

Percent LNGSMH variance due to LNPETROLITHALATI

Percent LNGSMH variance due to LNGSMH
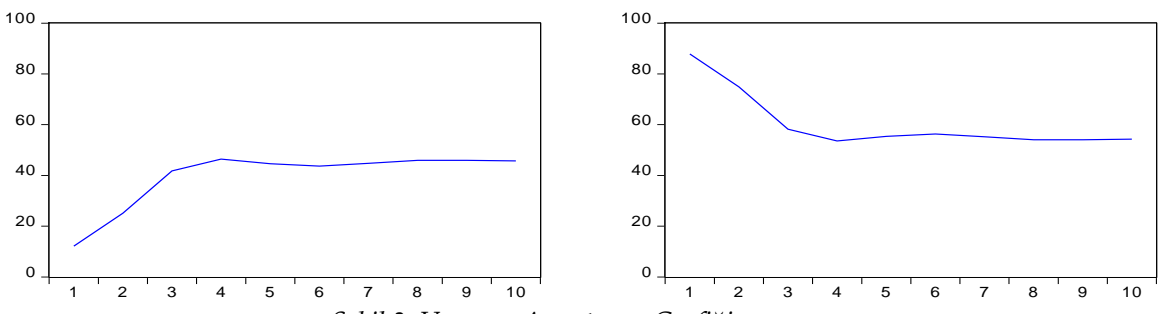

Şekil 3. Varyans Ayrıştırma Grafiği 


\section{Sonuç ve Değerlendirme}

Ham petrol ithalatı, bir ülkede kamu kesiminin ve özel kesimin enerji ihtiyacının karşılanmasında ve petrol destekli sektörlerin üretimlerinin devamlılığın sağlanmasında ulusal kaynakların yetersizliği nedeniyle ön plana çıkabilmektedir. İthalat teknik olarak bir ülkenin döviz rezervlerini azalttı̆̆ı gibi ulusal parasının da döviz karşısında değer kaybetmesi, yerli üreticinin zarar görmesi, işsizlik ve enflasyon gibi ekonomik göstergelerde değişimlere yol açabilmektedir. Bu etki sadece içsel ekonomik göstergelerin ötesinde makro anlamda dışsal ekonomik göstergeleri de etkileyebilmektedir. Bazı ülkeler için ithalat bir kalkınma modeli olarak ele alınırken söz konusu ithalatın yapıldığı sektörlerin ihracatçı yeteneğinin artması da beraberinde hedeflenmektedir. Dolayısıyla ithalatın bir ülkenin büyüme hızına ve oranlarına etkisi olabilmektedir.

$\mathrm{Bu}$ çalışmanın temel amacı ham petrol ithalatı ile büyüme arasındaki ilişkiyi analiz etmektir. Söz konusu çalışmaya dair literatürel inceleme yapıldığında birçok çalışma nihai bakımdan bazı göstergeler ile ham petrol arası ilişkiyi analiz ederken doğrudan ya da dolaylı olarak büyüme ile ilişkisini de analizlerine katmıştır. Bazı çalışmalar ise doğrudan ham petrol ithalatı ile büyüme arası ilişkiyi analiz etmiştir. Her bir çalışmada da söz konusu iki unsur arasında bir ilişkinin olduğu bulgularla ifade edilmiştir.

$\mathrm{Bu}$ çalışmada ise analizde kullanılan testlere göre, değişkenlerin ilk farklarında durağan oldukları, ardışık bağımlılık ve değişen varyans sorununun olmadığı, normal dağılımin mevcut olduğu ve büyümenin petrol ithalatı üzerinde önemli etkisinin olduğu bulgulanmıştır. Yine analiz sonuçlarına göre büyüme ve petrol ithalatı arasında uzun dönemli bir ilişki mevcuttur. Bunun yanında büyümeden petrol ithalatına doğru bir nedensellik bulgulanmıştır. Başka bir deyişle büyüme arttıkça petrol ithalatı artmaktadır. Bu durum literatür ile örtüşen bir sonuçtur. Büyüme arttıkça enerjiye olan talep de artacaktır. Petrol günümüz ekonomilerinde büyümenin sağlanması bakımından önemli bir girdi olarak karşımıza çımaktadır. Bu nedenle ithalat miktarının büyümeyi ne ölçüde belirlediğini öğrenmek önemlidir. Çalışma petrol ithalatı ile büyüme arasındaki tek yönlü nedenselliği göstermesi bakımından literatüre katkıda bulunmaktadır. 


\title{
EXTENDED ABSTRACT
}

\section{Crude Oil Imports and Growth}

\author{
Zehra Doğan Çalışkan - Mehmet Çakmak \\ Bolu Abant İzet Baysal University
}

According to the Factor Endowment (Heckscher-Ohlin) Theory in the international economics literature; a country acquires a comparative advantage in the production of those goods in which the production factor abundantly endowed by that country is extensively used. Thus, while exporting those specialized goods, it imports goods that are scarce. This theory mainly puts an emphasis on the economic growth of a country achieved by exporting those goods, that are produced in the sectors at which the country specializes in utilizing its abundantly endowed natural resources, to the countries where such resources are scarce. Today, some countries are exporters of crude petroleum, whereas some are importers. A portion of petroleum demand in Turkey is met by its underground resource, whereas a large portion of the demand for crude petroleum is imported. Imports of crude petroleum can meet the energy demand in a country, while a portion of the output provided by the use of the components of crude petroleum can be contributed to the economic growth at the same time. In this context, a relationship between the amount of petroleum imported and economic growth can be considered. This study introduces an analysis of the impacts of crude petroleum imports on economic growth. For this purpose, the study explicates the relationship between economic growth and crude petroleum imports in Turkey over the period of 1997-2017. Upon conducting a review on previous studies which examined the relationship between crude petroleum imports and economic growth, it is observed that the direct or indirect impacts of crude petroleum imports on economic indicators are examined in general. In some studies, the data of crude petroleum import and economic growth were also included in the analysis upon considering the elasticity of demand for imported crude petroleum. In some of those studies, the energy 
consumption and development analyses were carried out, while crude petroleum imports and economic growth were also interrelated. In some studies, however, such a relationship was addressed directly.

Theoretical and empirical literature revealed the close relationship between petroleum imports and economic growth. Accordingly, economic growth is expected to rise as crude petroleum imports increase. Nonetheless, petroleum imports may boost economic growth and increase the current account deficit due to energy payments. The contribution of this study to the literature has a distinguishable feature due to the testing of the long-term relationship between economic growth and the volume of petroleum imports. To this end, the data of crude petroleum imports and economic growth in Turkey obtained from the World Bank database over the period of 1997-2017 are utilized in the performed analysis. In order to test the relationship between these two variables, Vector Autoregressive Model (VAR), Granger Causality, Johansen Cointegration, Variance Decomposition, and Impulse-Response Analyses are carried out.

The analysis results can be stated briefly as follows: The first stage of the model involves the application of stationarity analysis to the series. The Augmented Dickey-Fuller (ADF) unit root test is performed on the series. Upon examining the stationarity of both variables, it is determined that the values of petroleum import and economic growth variables are not stationary at level, however, their first differences become stationary. The Johansen co-integration test is performed to investigate whether or not the variables are influenced by similar shocks. The obtained findings indicate that there are two cointegrated equations at the significance level of 0.05 . The results of the Granger Causality test conducted to determine the direction of the relationship between the variables reveal the existence of a unilateral causality running from economic growth towards petroleum imports. The appropriate lag length is required to be determined prior to the implementation of the VAR model. Therefore, the lag length is determined as 2 in accordance with the results of the relevant test criteria. The LM test is performed to determine whether or not the model contains autocorrelation, and it is determined that there is no autocorrelation problem in the model. 
It is also evaluated whether or not a heteroscedasticity problem exists in the model, and it is concluded that there is no heteroscedasticity according to the test results. The results of the Jarque-Bera Test, which indicate whether or not the error terms are normally distributed, reveal the presence of normal distribution. After the model passes the conformity tests, it is noticed that the economic growth variable has an impact on the petroleum import variable and it is also observed that the economic growth variable increases its share in the variance throughout ten consecutive periods, and therefore, it is an effective variable on the petroleum imports. By considering the impulse-response analysis, it can be observed how a one-unit standard shock in the GNP leads to a change in Petroleum Import. According to the results, 1 unit of standard shock in economic growth causes a shock of 0.18 units within the third period. Economic growth is an effective variable on petroleum imports. According to the Granger Causality Test of the VAR Model, it is also determined that there is a unilateral causality running from economic growth towards petroleum imports. The results indicate that economic growth is an effective variable on petroleum imports as expected.

The crude petroleum imports may loom large due to the lack of national resources to meet the energy needs of the public and private sectors in a country and to ensure the continuity of the production in petroleumbased sectors. Imports may reduce the foreign exchange reserves of a country, as well as it may lead to changes in economic indicators such as the depreciation of the national currency relative to foreign currency, losses of domestic producers, unemployment and inflation. This impact can influence not only the endogenous economic indicators but also the exogenous economic indicators in a macroeconomic sense. For some countries, imports are considered as a development model, while increasing the exporting capability of the importing sectors is aimed concurrently. Therefore, imports may have an impact on the economic growth rates of a country.

In this study, according to the tests used in the analysis, it is found that the variables are stationary at first differences, there is no autocorrelation and heteroscedasticity problem, the normal distribution is present, and economic growth has a significant impact on petroleum imports. According to the analysis results, again, there is a long-term relationship between 
economic growth and petroleum imports. Moreover, a causality running from economic growth towards petroleum imports is found. In other words, petroleum imports tend to increase as economic growth is boosted. This result is consistent with the relevant literature. As economic growth increases, the demand for energy would also increase. From a different perspective, the long-term relationship between petroleum imports and economic growth also plays a role in political decisions. The study contributes to the literature in terms of reporting the unilateral causality between petroleum imports and economic growth.

\section{Kaynakça / References}

Altinay, G. (2007). Short-run and long-run elasticities of import demand for crude oil in Turkey. Energy Policy, 35, 5829-5835.

Bostan, A. ve Ravanoğlu, A. (2018). Kırgızistan ekonomisinde ekonomik büyüme ve enerji tüketimi ilişkisi açısından sürdürebilir büyüme analizi. Ekonomi, Politika E Finans Araştırmaları Dergisi, 3(2), 181194.

Cheng-Yih, H. Ve Chen-Jung, H. (2018). Economic growth, oil consumption and import intensity: Factor decomposition of imported crude oil model approach. International Journal of Energy Economics and Policy, 8(4), 52-156.

Chien-Chiang L. ve Chun-Ping, C. (2007). The impact of energy consumption on economic growth: Evidence from linear and nonlinear models in Taiwan. Energy, Elsevier, 32(12), 2282-2294.

Çil Yavuz, N. (2005). Türkiye'de ihracat ve iktisadi büyüme arasında nedensellik analizi. Sosyal Siyaset Konferanslarn Dergisi, 49 (1), 961972.

Ediger, V.S. ve Berk, I. (2011). Crude oil import policy of Turkey: Historical analysis of determinants and implications since 1968. Energy Policy, 39, 2132-2142.

Ghosh, S.(2009). Import demand of crude oil and economic growth: Evidence from India. Energy Policy, 37, 699-702.

Hong, C.Y. ve Hsu, C. J. (2018). Economic growth, oil consumption and import intensity: factor decomposition of imported crude oil model approach. International Journal of Energy Economics and Policy, 8(4), 152-156. 
Hyun Seok, K. ve Jungho, B. (2013). Assessing dynamics of crude oil import demand in Korea. Economic Modelling, Elsevier, 35(C), 260-263.

Jabir, I. (2009). The dynamic relationship between the US GDP, imports and domestic production of crude oil. Applied Economics, 41, 31713178.

Kim, H.S. ve Baek, J. (2013). Assessing dynamics of crude oil import demand in Korea. Economic Modelling, 35, 260-263.

Lee, C.C. ve Chang, C. P. (2007). The impact of energy consumption on economic growth: Evidence from linear and nonlinear models in Taiwan. Energy, 32, 2282-2294.

Marbuah, G. (2017). Understanding crude oil import demand behaviour in africa: The Ghana case. Journal of African Trade, 4, 75-87.

Özaytürk, G. ve Alper, A. E. (2017). Petrol ithalatının cari açık üzerine etkisi: OECD ülkeleri üzerine bir analiz. Ankara Üniversitesi SBF Dergisi, 72(3), 513-524.

Özturk, İ. ve Arısoy, I. (2016). An estimation of crude oil import demand in Turkey: Evidence from time-varying parameters approach. Energy Policy, 99, 174-179.

Sun, X., Liu, C., Chen, X. ve Li, J. (2017). Modeling systemic risk of crude oil imports: Case of China's global oil supply chain. Energy, 121, 449-465.

Tiwari, A.K.(2015). On the dynamics of Indian GDP, crude oil production and imports. OPEC Energy Rewiev, 39(2), 162-183.

Uzunöz, M. ve Akçay, Y. (2012). Türkiye'de büyüme ve enerji tüketimi arasındaki nedensellik ilişkisi: 1970-2010. Çankırı Karatekin Üniversitesi Sosyal Bilimler Enstitüsü Dergisi, 3(2), 1-16.

Yapraklı S. ve Kaplan, F. (2015). Re-examining of the Turkish crude oil import demand with multi-structural breaks analysis in the long run period. International Journal of Energy Economics and Policy, 5(2), 402-407.

Zhang, C.P., Cao, X., Zhao, Y.N., Zhang, J. ve Yu, L. (2013). Research on the impact of international crude oil price fluctuation and oil import to China's. 2013 International Conference on Management Science $\mathcal{E}$ Engineering (20th), July 17-19, 2013 Harbin, P.R.China 
Ziramba, E. (2010). Price and income elasticities of crude oil import demand in South Africa: A cointegration analysis. Energy Policy, 38, 7844-7849.

Kaynakça Bilgisi / Citation Information

Doğan-Çalışkan, Z. ve Çakmak, M. (2019). Ham petrol ithalatı ve büyüme. OPUS-Uluslararası Toplum Araştırmaları Dergisi, 11(18), 935-955. DOI: 10.26466/opus.552784 